\title{
Implementation and evaluation of a weight-reduction programme for diabetic patients at a primary health care facility in the Western Cape: a pilot study
}

\author{
A Razak ${ }^{\text {iD }}$ and AA Isaacs ${ }^{a b *}$ \\ aMetro District Health Services, Cape Town, Western Cape, South Africa \\ ${ }^{b}$ Faculty of Health Sciences, Division of Family Medicine, University of Cape Town, Cape Town, South Africa \\ *Corresponding author, email: aaisaacs@westerncape.gov.za
}

Background: Diabetes is a common non-communicable disease and complications are resulting in increased disability, reduced life expectancy and enormous health costs for virtually every society. Medical Nutrition Therapy is important for the prevention, treatment, and self-management of diabetes, and the prevention or delay in onset of diabetes-related complications. The current nutritional guidelines for diabetes state that carbohydrates should comprise $45-60 \%$ of the total nutritional intake and that lowcarbohydrate or high-protein diets offer no long-term success over healthy eating plans. Recent studies suggest that there may be merit in using low-carbohydrate diets in diabetic patients for weight reduction and improved cardiovascular markers. This study aimed to implement and evaluate a pilot programme for weight loss in diabetes mellitus type 2 patients by comparing a low-carbohydrate diet with the conventional low-fat diet.

Methods: The study design was that of a two-group parallel design, with one group following a low-fat diet and the other a lowcarbohydrate diet. Diabetic patients attending the Mitchell's Plain Community Health Centre in Cape Town were recruited, with 10 participants in each group. Both groups received similar advice on exercise and behaviour change. Changes in weight, waist circumference, blood pressure and blood parameters (creatinine, lipids and $\mathrm{HbA} 1 \mathrm{c}$ ) were recorded at baseline and again after 12 weeks.

Results: There were reductions in weight (1.85 kg vs. $0.1 \mathrm{~kg}$ gain) and HbA1c (1.72 vs. 0.32 ) in the low-carbohydrate diet group when compared with the low-fat diet group. No significant change was seen in other parameters including BP, total cholesterol and serum creatinine for either group.

Conclusion: Low-carbohydrate diets may be effective in promoting weight loss and improving glucose control in diabetic patients. Implementation of this programme would require a paradigm shift for staff and further studies to assess its acceptability for patients.

Keywords: diabetes, implementation, low-carbohydrate diet, primary health care, weight loss

\begin{abstract}
Introduction
The Diabetic Atlas states that globally 382 million people have diabetes and that this will rise to 592 million by $2035 .{ }^{1}$ In South Africa the prevalence for diabetes is $9.27 \% .^{1}$ A study done in Bellville, Cape Town between 2008 and 2009 showed that the prevalence of diabetes mellitus (DM) type 2 increased more in the coloured community ( $28.2 \%$ compared with $7.1 \%$ in a 1999 study). ${ }^{2}$
\end{abstract}

The South African National Health and Nutrition Examination Survey in 2012 found the prevalence of overweight and obesity was significantly higher in females ( $39.2 \%$ and $24.8 \%$ respectively) compared with males $\left(20.1 \%\right.$ and $10.6 \%$ respectively). ${ }^{3}$ It also found that $\mathrm{HbA} 1 \mathrm{c}$ values were higher $(>6 \%)$ within the coloured and Asian/Indian population. ${ }^{3}$ Raised $\mathrm{HbA} 1 \mathrm{c}$ values amongst coloured diabetics were further supported by data from the 2013 chronic disease audit of Mitchells Plain Community Health Centre. ${ }^{4}$ This audit showed that, of the recorded $\mathrm{HbA} 1 \mathrm{c}(60 \%$ of the sample), all were over 7 , this despite $70 \%$ of the sample being educated regarding diet and exercise.

The current Society for Endocrinology, Metabolism and Diabetes of South Africa (SEMDSA) guidelines state that Medical Nutrition Therapy (MNT) is important for the prevention, treatment and self-management of diabetes, and the prevention or delay in onset of diabetes-related complications. ${ }^{5}$ MNT can reduce $\mathrm{HbA} 1 \mathrm{c}$ by $1-2 \%$, depending on the duration of diabetes. ${ }^{5}$
The current nutritional guidelines for DM state that carbohydrates should make up $45-60 \%$ of the total nutritional intake and that low-carbohydrate or high-protein diets offer no long-term success over healthy eating plans. ${ }^{5}$ Recent studies suggest that there may be merit in implementing a low-carbohydrate diet in diabetic patients. ${ }^{6-17}$

A two-year randomised control trial (2008) compared weight loss on a low-carbohydrate diet with a Mediterranean or low-fat diet amongst 322 participants. ${ }^{6}$ The low-carbohydrate group consumed the smallest amount of carbohydrates and the largest amounts of fat, protein and cholesterol. The study concluded that the Mediterranean and low-carbohydrate diets are safe and may be effective alternatives to weight loss compared with lowfat diets. The mean weight loss was $2.9 \mathrm{~kg}$ for the low-fat groups, $4.4 \mathrm{~kg}$ for the Mediterranean group and $4.7 \mathrm{~kg}$ for the lowcarbohydrate group.

A study done in Philadelphia (2004) randomly placed 132 severely obese subjects (39\% were diabetic) on either a lowcarbohydrate or low-fat, calorie-restricted diet.7 Seventy-nine subjects completed the six-month study. The results showed that subjects on the low-carbohydrate diet lost more weight than the low-fat diet group (mean weight loss $5.8 \mathrm{~kg}$ vs. $1.9 \mathrm{~kg}$, $p=0.002$ ). Insulin sensitivity, measured only on non-diabetic 


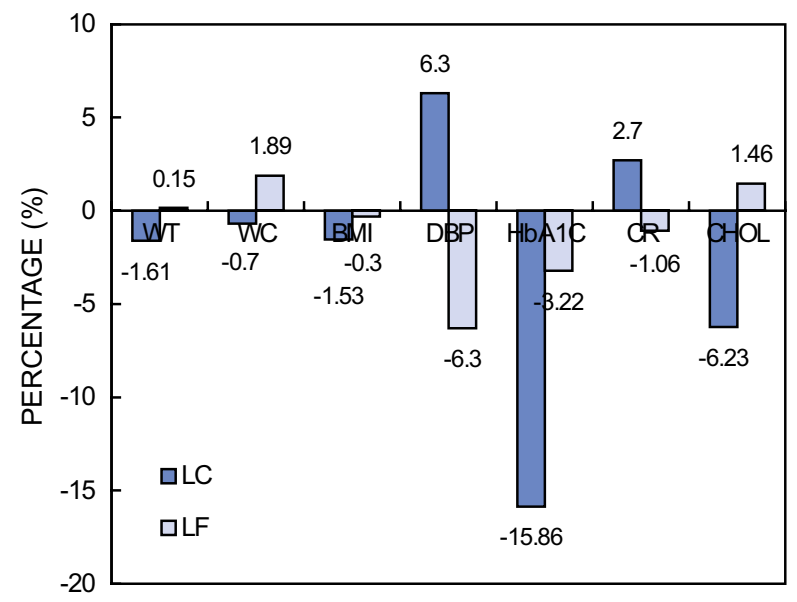

Figure 1: Percentage change after week 12 for the various indicators.

subjects, also showed better improvement as did triglyceride levels in the low-carbohydrate group.

To address the concern regarding the effect of high-protein diets on the kidney, a two-year randomised controlled trial was carried out between 2003 and 2007 in three medical centres in the USA. ${ }^{8}$ A total of 307 obese (body mass index [BMI] 30-40) adults were recruited and randomly assigned to one of the two diets and followed up for 3, 12 and 24 months. It concluded that in healthy obese individuals, a low-carbohydrate, high-protein weight-loss diet over two years was not associated with noticeably harmful effects on glomerular filtration rate (GFR), albuminuria, or fluid and electrolyte balance compared with a low-fat diet.

A recent study compared traditional high-fibre weight-loss (50\% carbohydrate, $20 \%$ protein) diets with relatively high-protein (30\% protein $40 \%$ carbohydrate) weight-loss diets in overweight or obese women. ${ }^{9}$ Results showed that both groups achieved weight loss, reduced body fat, reduced weight circumference and reduced total cholesterol, low density lipoprotein cholesterol (LDL) and triglycerides (TG). Both groups also showed improvement in blood pressure and fasting plasma glucose. The high-protein group, however, showed better results in all of the above parameters.

A review article published in 2005 looked at evidence from various randomised controlled trials regarding safety and efficacy of low-carbohydrate diets for diabetic patients..$^{10}$ They concluded that such diets are safe and effective and can be comparable or better than traditional low-fat carbohydrate diets in reducing weight, improving dyslipidaemia, reducing blood pressure, reducing triglycerides and increasing high-density lipoprotein (HDL) cholesterol.

A systematic review and meta-analysis of clinical trials of the effects of low carbohydrate diets (LCD) on cardiovascular risk factors was published in 2012. ${ }^{11}$ It reviewed a total of 23 reports corresponding to 17 clinical investigations. Meta-analysis carried out on data obtained in 1, 141 obese patients showed LCD to be associated with significant decrease in body weight, BMI, abdominal circumference, systolic blood pressure, diastolic blood pressure, plasma triglycerides, fasting plasma glucose, $\mathrm{HbA1c}$, plasma insulin and plasma C-reactive protein and an increase in HDL cholesterol.
A systematic review (2012) of observational studies reviewed the relationships between dairy fat and high-fat dairy foods on obesity and cardiovascular risks. ${ }^{12}$ Results showed that in 11 of the 16 studies high fat intake was inversely associated with measures of adiposity. The review concluded that evidence does not support the hypothesis that dairy fat or high-fat dairy foods contribute to obesity or cardiovascular risk.

A 12-month randomised control trial (2003) compared four popular weight-loss diets among 311 free-living overweight or obese (BMI 27-40), non-diabetic premenopausal woman. ${ }^{13}$ The four diets were known as the Atkins (high protein/low carbohydrate), Zone (40\% carbohydrate, $30 \%$ protein, 30\% fat), LEARN (prudent diet 60\% carbohydrate) and Ornish (10\% fat) diets. Primary outcome was weight loss and secondary outcomes were, among others, lipid profile and blood pressure. The results showed that mean weight loss was significantly higher in the Atkins group $(-4.7 \mathrm{~kg}$ compared with LEARN $-2,7 \mathrm{~kg}$, Ornish $-2.2 \mathrm{~kg}$, Zone $1.6 \mathrm{~kg}$ ). The study concluded that low-carbohydrate, high-protein, high-fat diets may be a feasible alternative to conventional weight-loss strategies.

In 2003, a randomised control trial (RCT) compared a lowcarbohydrate diet with a calorie-restricted diet for cardiovascular risk factors. ${ }^{14}$ The low-carbohydrate group showed a greater loss of weight at a mean weight loss of $8.5 \mathrm{~kg}(p \leq 0.001)$. Mean blood pressure, lipids, fasting glucose and insulin were at normal values at the beginning of the trial and improved in both groups with no significant differences.

In 2004, an RCT compared a national (USA) cholesterol education programme diet with a diet lower in carbohydrates and higher in protein and monosaturated fats. ${ }^{15}$ Results of the trial showed that the low-carbohydrate group lost more weight $(13.6 \mathrm{lb} / 6.2 \mathrm{~kg})$ compared with the national cholesterol education programme diet group $(7.5 \mathrm{lb} / 3.4 \mathrm{~kg}$ ). Favourable blood lipid changes were also noted in the low-carbohydrate group.

More recently a systematic review and meta-analysis published in PlosOne 2014 compared low carbohydrate with isoenergetic balanced diets for reducing weight and cardiovascular risk. ${ }^{16}$ The study showed that among type 2 DM patients few differences were found with regard to weight loss, cardiovascular risk and glycaemic control.

A randomised parallel group compared a low-carbohydrate diet ( $<40 \mathrm{~g}$ total carbohydrate minus fibre) with a low-fat diet $(<30 \%$ fat of total energy intake) among a total of 148 participants. ${ }^{17}$ Results showed that after 12 months the low carbohydrate group had greater reduction in weight $(p=0.002)$, fat mass $(p=0.011)$ and triglyceride level $(p=0.038)$, and had greater increases in HDL $(p<0.001)$.

\section{Aim and objectives}

\section{Aim}

The study aimed to implement and evaluate a pilot programme for weight loss in DM type 2 patients.

\section{Objectives}

(1) Implement a weight loss programme for DM type 2 patients in two parallel patient groups, i.e. 
low-carbohydrate diet (Addendum 1) and a conventional low-fat diabetic diet (Addendum 2).

(2) Measure effects of programme on changes in weight, waist circumference, blood pressure and blood parameters (creatinine, lipids and $\mathrm{HbA} 1 \mathrm{c}$ ).

(3) Make recommendations for implementation at other PHC facilities.

\section{Methodology}

The study was a two-group parallel design performed at Mitchell's Plain CHC between January and December 2015. Overweight or obese (BMI > 25) DM type 2 patients attending the Mitchell's Plain $\mathrm{CHC}$ were invited using leaflets, posters and via staff to participate in the programme. The inclusion criteria were as follows: DM type 2 for at least one year, age 18-65 years, BMI $>25$, ability to attend clinics for follow-up, adherent to current medications (was checked from attendance rates, interviews). Exclusion criteria were similar to studies discussed in the literature review, i.e. in the Mediterranean study in Israel ${ }^{6}$ and Philadelphia study ${ }^{7}$ where pregnancy/lactation, abnormal serum creatinine (> $90 \mu \mathrm{mol} / \mathrm{l})$, severe dyslipidaemia (> $7.5 \mathrm{mmol} / \mathrm{l})$, liver disease (Increased ALT), malignancy, GIT abnormalities (e.g. inflammatory bowel disease, peptic ulcer disease), currently on another trial or weight-loss programme were excluded.

Sampling technique was non-probability consecutive sampling. The first 10 patients who met the inclusion criteria were assigned to the low-carbohydrate group and the next 10 patients were assigned to the low-fat group. Written informed consent was obtained from all participants. Both groups received education regarding their specific diet, and similar advice regarding exercises and motivation for change. All patients received two sessions early in the programme and a final follow-up session after 12 weeks. All sessions were facilitated by the researchers. The low-carbohydrate (LC) group consisted only of females while the low-fat (LF) group had 2 males and 8 females. Average age of the low-carbohydrate group was 49.2 years (range 42 to 66 years) and for the low-fat group it was 49.6 years (range 35 to 59 years).

\section{Session 1 (week 0):}

- Diets explained to participants (Addendum 1 and 2)

- Answer questions and concerns about diets

- Motivational talk to mentally prepare for change

- Introduce three simple exercises (10-15 $\mathrm{min}$ ) to be done four times a week ${ }^{18}$
- Initial parameters and bloods taken (if bloods were taken within last six months they were used to save costs)

- Consent signed

- Diet implemented

Session 2 (week 2):

- Check understanding of diets

- Continue motivation for change

Session 3 (week 12):

- Discussion of results and feedback from patients and staff.

Parameters recorded at week 0 and week 12 were weight/BMI, blood pressure, $\mathrm{HbA} 1 \mathrm{c}$, creatinine, total cholesterol and waist circumference.

All continuous variables were normally distributed and displayed using means with standard deviations. Differences between baseline and week 12 results were assessed using paired Student's t-test. Data were entered in Excel $^{\circledR}$ (Microsoft Corp, Redmond, WA, USA) and analysed using STATA version $13^{\circledR}$ (StataCorp LP, 2013, College Station, TX, USA).

\section{Ethical considerations and reporting of results}

Ethical oversight for the study was obtained from the Ethics and Research Committee, Faculty of Health Sciences of the University of Cape Town. Approval for the study was obtained from the Provincial Research Committee, director of the Mitchell's Plain Sub-Structure as well as from the facility manager of Mitchells Plain CHC. Individual patients signed consent and confidentiality was maintained by the researchers. There was no conflict of interest for any of the research investigators.

\section{Consideration of beneficence}

The aim of the study was to implement a weight-loss programme that could assist and improve quality of life for each of the participants and subsequently reduce risk for complications of diabetes. If successful the programme could be implemented at other $\mathrm{CHCs}$ thus improving outcomes for a greater population and reducing the burden of disease.

\section{Consideration of potential harm}

Some concerns were raised regarding weight loss through ketosis and the effect of a higher protein diet on renal function. ${ }^{8}$ The literature does not support any significant dangers of an

Table 1: Comparison of indicators for the diets at baseline (week 0 ) and after 12 weeks

\begin{tabular}{|c|c|c|c|c|c|c|c|c|c|c|c|c|}
\hline & \multicolumn{6}{|c|}{ Low carbohydrate diet (LC) } & \multicolumn{6}{|c|}{ Low fat diet (LF) } \\
\hline & $\begin{array}{l}\text { W } 0 \\
\text { Mean }\end{array}$ & $\begin{array}{l}\text { W } 12 \\
\text { Mean }\end{array}$ & $\begin{array}{c}\text { Mean } \\
\text { change }\end{array}$ & W O SD & W 12 SD & $p$-value & $\begin{array}{c}\text { W } 0 \\
\text { Mean }\end{array}$ & $\begin{array}{l}\text { W } 12 \\
\text { Mean }\end{array}$ & $\begin{array}{c}\text { Mean } \\
\text { change }\end{array}$ & W 0 SD & W 12 SD & $p$-value \\
\hline Weight (kg) & 114.6 & 112.75 & -1.85 & 21.3 & 20.46 & 0.037 & 87 & 87.1 & +0.1 & 10.6 & 10.4 & 0.81 \\
\hline $\begin{array}{l}\text { Waist Circum- } \\
\text { ference }(\mathrm{cm})\end{array}$ & 129.2 & 128.3 & -0.9 & 10.8 & 9.42 & 0.31 & 106 & 106.2 & +0.2 & 7.37 & 6.61 & 0.37 \\
\hline BMI & 45.6 & 44.9 & -0.7 & 7.79 & 7.68 & 0.132 & 33.1 & 33.2 & -0.1 & 3.70 & 3.66 & 0.34 \\
\hline $\begin{array}{l}\text { Diastolic BP } \\
(\mathrm{mm} / \mathrm{Hg})\end{array}$ & 78.4 & 84.4 & -6 & 9.24 & 5.92 & 0.076 & 78.5 & 73.5 & 5 & 8.69 & 12.3 & 0.19 \\
\hline $\mathrm{HbA1c}(\%)$ & 10.84 & 9.12 & -1.72 & 2.417 & 2.42 & 0.006 & 9.93 & 9.61 & -0.32 & 1.71 & 1.94 & 0.558 \\
\hline $\begin{array}{l}\text { Creatinine } \\
(\mu \mathrm{mol} / \mathrm{l})\end{array}$ & 59.2 & 60.8 & +1.6 & 18.01 & 21.27 & 0.75 & 66 & 65.3 & -0.7 & 16.03 & 26.39 & 0.86 \\
\hline $\begin{array}{l}\text { Cholesterol } \\
(\mathrm{mmol} / \mathrm{l})\end{array}$ & 4.97 & 4.66 & -0.31 & 1.08 & 1.02 & 0.38 & 4.88 & 4.8 & 0.08 & 1.77 & 1.49 & 0.79 \\
\hline
\end{tabular}


LCD. During the study period no patient showed any signs of deteriorating health. One patient on the low-fat diet programme showed worsening renal function that was appropriately managed and referred.

\section{Results}

Table 1 summarises the indicators for the diets at baseline and after 12 weeks and Figure 1 shows the percentage change for each indicator. At week 12 the LC group showed a statistically significant average weight loss of $1.85 \mathrm{~kg}(p=0.03)$ compared with the LF group, showing an average weight gain of $0.1 \mathrm{~kg}(p=$ 0.8). The largest weight loss in the LC group was $6 \mathrm{~kg}$ compared with $2 \mathrm{~kg}$ in the LF group.

An average reduction in waist circumference in the LC group was $0.9 \mathrm{~cm}$ compared with an increase of $0.2 \mathrm{~cm}$ in the LF group. These results, however, were not statistically significant with $p=$ 0.3 in the LC group compared with $p=0.7$ in the LF group.

Average BMI depicted a fall in the LC group of 0.7 compared with 0.1 in the LF group. This was not statistically significant with $p=$ 0.132 in the LC group compared with $p=0.34$ in the LF group.

According to SEMDSA, the systolic target of $130 \mathrm{~mm} \mathrm{Hg}$ in type 2 DM has always been an extrapolated one with no direct evidence of benefit from randomised trials. ${ }^{5}$ It was therefore decided to focus on changes in diastolic blood pressure (DBP). The LC group showed an increase in DBP while the LF group showed a decline. This increase was, however, within the normal range of DBP. None of the values showed significance with a $p$-value of 0.076 in the LC group and 0.19 in the LF group.

At week 0 the average $\mathrm{HbA} 1 \mathrm{c}$ was 10.84 in the LC group compared with 9.93 in the LF group. At week $12 \mathrm{HbA} 1 \mathrm{c}$ fell by 1.72 in the LC group as opposed to 0.32 in the LF group. The results in the LC group were statistically significant with a $p$-value of 0.006 ; this was not reflected in the LF group 2 with $p=0.55$.

Creatinine remained stable except for one patient in the LF group showing a jump to 118 . Differences in average values were not statistically significant in both groups with $p=0.75$ in the LC group and $p=0.86$ in the LF group.

Total cholesterol showed little difference between the two groups and between baseline and after week 12. This was reflected by $p$-values of 0.38 and 0.79 respectively.

\section{Discussion}

Despite the small sample size some indicators, perhaps the most important ones (weight and $\mathrm{HbA} 1 \mathrm{c}$ ), showed significant change. $\mathrm{HbA1c}$ remains an important predictive factor in prognosis for diabetic patients. ${ }^{5}$ Insignificant changes to BP, cholesterol and creatinine were welcomed as these were stable throughout the study. A 2003 randomised control trial done in Cincinnati, USA, ${ }^{14}$ and the Tulane University study ${ }^{17}$ showed similar significant results with regard to weight loss.

The major weakness of the study was the small sample size as it was a pilot study. In the low-fat group, patients may have lacked motivation as the diet proposed was already something they were familiar with and did not achieve weight loss previously. Much care was taken to motivate both groups similarly but the low-carbohydrate diet may have seemed more novel as it allowed patients a newer approach to weight loss. Although patients verbally confirmed that they followed the diets, we could not guarantee or measure that they followed diet guidelines closely.

Important questions remain around the cost and convenience of low-carbohydrate diets. Cost may be balanced by using cheaper proteins like beans and aval. Rawer and natural ways of eating could also be cheaper than processed foods. The notion also exists that over time hunger and cravings will subside and patients will, as a whole, consume less and thus spend the same amount of money. The long-term implications from fewer diabetic-related complications could benefit patients and decrease government expenditure. Further research is needed to quantify such benefits as well as qualitative aspects of adhering to the diet over a longer period.

Recommendations include training staff at facilities in our subdistrict on understanding and implementing low-carbohydrate diets, larger studies involving more facilities and using patients who have benefited from the diet to share their successes with others.

\section{Conclusion}

Current evidence favours the low-carbohydrate diets for weight loss and improving cardiovascular risk factors in diabetic patients. Results from this pilot study as well as from the literature deem it safe to offer patients a low-carbohydrate option to optimise the nutritional aspect of diabetic care. Implementation of this programme would require a paradigm shift for staff and further studies to assess its acceptability for patients.

\section{ORCID}

A Razak (D) http://orcid.org/0000-0001-7371-2429

\section{References}

1. Diabetic Atlas. 6th ed. International Diabetes Federation, 2013. www. idf.org/diabetesatlas.ISbn:2-930229-85-3

2. Erasmus RT, Soita DJ. High prevalence of diabetes mellitus and metabolic syndrome in a South African coloured population: Baseline data of a study in Bellville, Cape Town. SAMJ. 2012;102 (11):841-4.

3. Shisana O, Labadarios D et al. South African Health and Nutrition Survey. Cape Town: HSRC Press; 2013.

4. Chronic disease audit. MPCHC 2013; Cape Town: Western Cape Department of Health.

5. Amod A, Ascott Evans BH, Berg Gl et al. The 2012 Society for Endocrinology, Metabolism and Diabetes of South Africa. JEMDSA 2012;17(2 Suppl 1):S1-95.

6. Shail,SwarzfuchsD, HenkinYetal.WeightLosswithaLowCarbohydrate, Mediterranean or Low Fat Diet. N Engl J Med. 2008 July;359 (3):229-41. https://doi.org/10.1056/NEJMoa0708681

7. SamahaFF, IqbalN,SeshadriPetal.ALowCarbohydrateas Compared to Alowfat dietin SeverObesity.NEnglJMed.2003May;348(21):2074-81. https://doi.org/10.1056/NEJMoa022637

8. Friedman AN, Ogden LG, Foster GD, et al. Comparative effects of low carbohydrate high protein versus low fat diets on the kidney. Clin J Am Soc Nephrol. 2012 July;7 (7):1103-11. https://doi.org/10.2215/ CJN.11741111

9. Te Morenga LA, Levers MT, Williams SM, et al. Comparison of High Protein and Higher Fibre weight loss diets in Woman with Risk Factors for the Metabolic Syndrome. Nutr J. 2011;10 (1):40 https://doi.org/10.1186/1475-2891-10-40

10. Arora SK, Mcfarlane ST. The case for low carbohydrate diets in diabetes management. Nutr Metabol. 2005 July;2 (1):16. https://doi.org/10.1186/1743-7075-2-16 
11. Santos FL, Esteves SS, de Costa A, et al. Systematic review and metal analysis of clinical trials of the effects of low carbohydrate diets on cardiovascular risk factors. Obes Rev. 2012;13 (11):1048-66. https://doi.org/10.1111/obr.2012.13.issue-11

12. Kratz M, Baars T, Guyenet $S$. The relationship between high fat dairy consumption and obesity, cardiovascular and metabolic disease. Eur J Nutr. 2012 Feb;52(1):1-24.

13. Garder C, Kiazand A, Alhassan S. Comparison of the atkins, zone, ornish, and LEARN Diets for Change in weight and related risk factors among overweight premenopausal women. J Am Med Assoc. 2007 March;297 (9):969-77. https://doi.org/10.1001/jama.297.9.969

14. Brehm B, Seeley R, Daniels SR. A randomised trial comparing a very low carbohydrate diet and a calorie restricted low fat diet on body weight and cardiovascular risk factors in healthy woman. J Clin Endocrinol. 2003;88 (4):1617-23. https://doi.org/10.1210/jc.2002021480
15. Ande YW, Agatson AS, Jimenez FL. The national education program diet versus a diet lower in carbohydrate and higher in protein and monounsaturated fat. Arch Int Med. 2004;164 (19):2141-6.

16. Nause CE, Schoones A, Maryanne S, et al. Low Carbohydrate versus isoenergetic balanced diets for reducing weight and cardiovascular risk: A systematic review and meta-analysis. PLoSOne. 2014;9 (7):e100652.

17. Bazzano LA, Hu T, Reynolds, K, et al. Effects of low-carbohydrate and low fat diets. Ann Int Med. 2014;161 (5):309-18. https://doi. org/10.7326/M14-0180

18. Ferris T. The 4-hour body. New York, NY: The Random House Group; 2010.

Received: 05-02-2017 Accepted: 01-05-2017

\section{Addendum 1}

Simple low carbohydrate diet plan ${ }^{18}$ :

The main aim of the diet is to reduce carbohydrate intake and supplement it with larger quantities of protein and vegetables.

(1) Avoid 'white' carbohydrates
(a) All breads (including brown) and cereal
(b) Roti, pasta and tortillas
(c) All rice
(d) All fried food with breading/crumbs
(e) Potatoes, sweet potatoes.

(2) What to eat:
(a) Proteins
(i) Eggs, chicken, beef, lamb, mutton, fish, pork
(b) Legumes
(i) Lentils, beans, 'daal'
(c) Vegetables
(d) all except those listed above

No restrictions on food listed above

(3) Avoid carbohydrate rich drinks-all gas drinks

(a) Drink tea/coffee with no sugar ( substitute with cinnamon)

(b) Limit aspartame 'zero' drinks

(c) Red wine permissible in moderation

(4) Avoid fruits

(5) Eat meals +- 4 hrs apart

Snacks: Yogurt, Nuts, Biltong 


\section{Addendum 2}

Simple low-fat eating plan (adapted from DMSA)

\begin{tabular}{|c|c|c|}
\hline Food group & Include: low-sugar, lower calorie foods & Exclude/limit: higher fat/sugar, higher calorie foods \\
\hline Dairy and dairy products & $\begin{array}{l}\text { Skimmed or low-fat milk in liquid or powder form, } \\
\text { skimmed milk powders, low-fat buttermilk, natural (plain) } \\
\text { low-fat yoghurt }\end{array}$ & $\begin{array}{l}\text { Condensed and evaporated milk, full-cream natural (plain) yoghurt, milk- } \\
\text { shakes, flavoured milk drinks }\end{array}$ \\
\hline Fats & $\begin{array}{l}\text { Avocado pears, all types of nuts, peanuts, peanut butter } \\
\text { (sugar free) olive oil, olives, canola oil, canola margarine, } \\
\text { olive oil margarine }\end{array}$ & $\begin{array}{l}\text { Hard cooking fat, hard (brick margarine), bacon, full-fat mayonnaise and } \\
\text { cream, coconut oil, coconut milk, coconut cream, cream, ice-cream }\end{array}$ \\
\hline \multirow[t]{7}{*}{ Proteins } & Fish: All types - smoked, fresh or frozen (not fried in oil) & $\begin{array}{l}\text { Fish: Covered in crumbs, flour and egg or dough, deep fried in oil, ov- } \\
\text { en-baked fish portions - battered or crumbed }\end{array}$ \\
\hline & Poultry: Chicken and turkey without skin - not fried & Chicken: chicken and turkey with skin, fried crumbed chicken, e.g. Kentucky \\
\hline & $\begin{array}{l}\text { Legumes: Beans, peas, chick peas and lentils (cooked/ } \\
\text { canned) }\end{array}$ & Red meat: Fatty beef, pork, mutton and lamb \\
\hline & $\begin{array}{l}\text { Lean red meat, lean cold meats, organ meats: liver, kidneys } \\
\text { (not fried) }\end{array}$ & Liver spreads, fried liver, liver pate, and liver sausages. \\
\hline & Lean biltong (fat removed) & Fried eggs \\
\hline & $\begin{array}{l}\text { Eggs: Boiled, poached, omelette, scrambled - limit to two } \\
\text { to four eggs per week }\end{array}$ & High-fat cheeses \\
\hline & Low-fat cheese & Cereals: Weetabix, Cornflakes, Rice Crispies, \\
\hline \multirow[t]{6}{*}{ Grains, Cereals, Breads } & $\begin{array}{l}\text { Porridges: Bokomo oats, rolled oats, oat bran, and whole- } \\
\text { grain breakfast cereals }\end{array}$ & all baking products made from white bread and white cake flour \\
\hline & Heavy breads such as health breads and seed loaves & Baked desserts \\
\hline & Pasta made from durum wheat & Low-fibre crackers \\
\hline & Crushed wheat, popcorn & Potatoes \\
\hline & Baby potatoes, sweet potato - boiled, & Sushi rice, risotto rice \\
\hline & Legumes: dried beans, peas, lentils, chick peas, soya beans & \\
\hline \multirow[t]{2}{*}{ Fruits and vegetables } & ALL fresh fruit & $\begin{array}{l}\text { Fruit canned in syrup, all fruit juices, vegetables served with hard, margarine, } \\
\text { butter or cream }\end{array}$ \\
\hline & ALL fresh or frozen vegetables & \\
\hline
\end{tabular}

